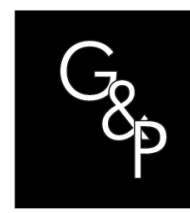

THEMATIC SECTION: STATISTICAL PROCESS MONITORING AND CONTROL

\title{
Monitoring multinomial processes based on a weighted chi-square control chart
}

\section{Monitoramento de processos multinomiais com base em um gráfico de controle qui-quadrado ponderado}

\author{
Achouri Ali ${ }^{1}$ (D), Emira Khedhiri², Ramzi Talmoudi ${ }^{3}$ (D), Hassen Taleb ${ }^{1}$ \\ ${ }^{1}$ University of Carthage, ARBRE Laboratory, Tunis, Tunisia. \\ ${ }^{2}$ University of Tunis, ARBRE Laboratory, Tunis, Tunisia. \\ ${ }^{3}$ University of Carthage, ENVIE Laboratory LR18ES48, Nabeul, Tunisia.
}

How to cite: Achouri, A., Khedhiri, E., Talmoudi, R., \& Taleb, H. (2021). Monitoring multinomial processes based on a weighted chi-square control chart. Gestão \& Produção, 28(3), e43. https://doi.org/10.1590/18069649-2021v28e43

\begin{abstract}
Interpreting an out-of-control signal is a crucial step in monitoring categorical processes. For the Chi-Square Control Chart (CSCC), an out-of control situation does not specify if it was a process deterioration or a process improvement. For this reason, a weighted chi-square statistical control chart WSCC is proposed with different weighting categories in order to enable an accelerated disclosure of a control situation after a shift due to a deterioration of quality and on the other hand, decelerate an out of control situation after a shift due to a quality improvement. Furthermore, in comparison with Marcucci's method, the new procedure provides an accurate and easier way to interpret several signals. In other words, the WSCC allows a faster detection of an out-of control situation in the case of a quality deterioration, however, an out-of control situation is not quickly detected in the case of a quality improvement. Indeed, comparative studies have been performed to find the best control chart for each combination. Concluding remarks with comments and recommendations are given based on Average Run Length (ARL) and standard deviation run length (SDRL).
\end{abstract}

Keywords: Multinomial processes; Categorical processes; Chi-square control chart; Weighted chisquare statistic; ARL and SDRL.

Resumo: Interpretar um sinal fora de controle é uma etapa crucial no monitoramento de processos categóricos. Para o gráfico de controle do qui-quadrado (CSCC), uma situação fora de controle não especifica se foi uma deterioração do processo ou uma melhoria do processo. Por esta razão, um gráfico de controle estatístico qui-quadrado ponderado WSCC é proposto com diferentes categorias de ponderação, a fim de permitir uma divulgação acelerada de uma situação de controle após uma mudança devido a uma deterioração da qualidade e, por outro lado, desacelerar uma situação fora de controle após um turno devido a uma melhoria da qualidade. Além disso, em comparação com o método de Marcucci, o novo procedimento fornece uma maneira precisa e mais fácil de interpretar vários sinais. Em outras palavras, o WSCC permite uma detecção mais rápida de uma situação fora de controle no caso de uma deterioração da qualidade, entretanto, uma situação fora de controle não é detectada rapidamente no caso de uma melhoria da qualidade. Na verdade, estudos comparativos foram realizados para encontrar o melhor gráfico de controle para cada combinação. As observações finais com comentários e recomendações são fornecidas com base no comprimento médio de execução ( $A R L$ ) e comprimento de execução de desvio padrão (SDRL).

Received July 30, 2020 - Accepted Oct. 16, 2020

Financial support: None.

This is an Open Access article distributed under the terms of the Creative Commons Attribution License, which permits

unrestricted use, distribution, and reproduction in any medium, provided the original work is properly cited. 
Palavras-chave: Processos multinomiais; Processos categóricos; Gráfico de controle quiquadrado; Estatística qui-quadrado ponderada; ARL e SDRL.

\section{Introduction}

Throughout the years, the importance of measurement and improvement of quality was enhanced in the investigation of continuous improvement of products and services. The use of statistical process control (SPC) via control charts has proven its efficiency in monitoring and improving manufacturing processes. The most commonly used SPC charts are those of Shewhart (1925). Shewhart \& Deming (1939) discussed Statistical method of quality control. There are two different types of control charts which differ depending on the nature of the control characteristic. If the quality dimension is measured through a numerical scale, then a control chart by variables is used. On the other hand, if the product can only be categorized as defective or non-defective, control chart by attributes is applied. Steiner et al. (1996) proposed control charts to detect mean and standard deviation shifts based on grouped data. For the second case, Duncan (1950) developed a chi-square chart for controlling a set of percentages. The main purpose of this work is to focus on the attribute control chart. The attribute control chart is applied if the quality cannot be measured with numerical scale, such as appearance, softness, color, etc. Nelson (1987) investigated chi-square control chart for several proportions and Woodall (1997) discussed construction methods of control charts based on attribute data. Product units are then classified as either conforming or nonconforming, depending upon whether or not they meet specifications. The binary classification used in the p-chart might not be applied in several situations where product quality does not transform suddenly from conforming to nonconforming, and there might be a number of intermediate states such as conforming, minor nonconforming and major non-conforming. Hence with many categories of classification, the process develops multinomial random variables. Several researches were conducted in order to monitor such processes like Marcucci (1985), Raz \& Wang (1990) and Taleb \& Limam (2002). A Control charts for process average and variability based on linguistic data was proposed by Kanagawa et al. (1993), on the other hand, Tucker et al. (2002) analyzed control chart method for ordinal data. Taleb et al. (2006) discussed methods based on multivariate fuzzy multinomial control charts. Topalidou \& Psarakis (2009) reviewed multinomial and multi-attribute quality control charts. The previous studies do not provide an idea about which category is responsible for the out-of-control situation and could not detect if it is a process deterioration or not. For this reason, a new chart using a Weighted Sum of Chi-squares that express the relative importance of all categories and with known quality proportions is proposed. Consequently, an efficient way is presented to interpret out-of-control signals. Classical control chart for attribute processes is discussed in Section 2. The framework for the proposed Weighted Sum of Chi-Square chart is presented in Section 3. An experimental study and a sensitivity analysis are given in Section 4 and 5 to illustrate the effectiveness of the new approach and compare it to the classical one.

\section{Control chart for attribute processes}

Marcucci (1985) introduces data where samples are classified into 3 categories such as conforming, non-conforming type $\mathrm{A}$ and non-conforming type $\mathrm{B}$, with baseline proportions 0:95, 0:03 and 0:02 respectively. Table 1 shows simulated data using the Marcucci example parameters. The Marcucci procedure uses as a test statistic the chisquare statistic and is defined in two cases as follows: 
- If such proportion $\pi$ is unknown, then a common statistical task is on homogeneity testing of proportions between the base period and each monitoring period (Duncan, 1974), and the correspondingly test statistic is expressed as follows (Equation 1):

$S_{i}^{2}=\sum_{k=i, 0} \sum_{j=1}^{t} \frac{n_{k}\left(\frac{X_{k j}}{n_{k}}-\frac{\left(X_{i j}+X_{0 j}\right)}{n_{i}+n_{0}}\right)^{2}}{\frac{X_{i j}+X_{0 j}}{n_{i}+n_{0}}}=n_{i} n_{0} \sum_{j=1}^{t} \frac{\left(\pi_{i j}-\pi_{0 j}\right)^{2}}{X_{i j}+X_{0 j}}$

where $X_{k j}$ is the number of items of category $j$ in sample $k, n_{k}$ is the size of sample $k$ and $\pi_{\mathrm{kj}}$ is the proportion of category $\mathrm{j}$ in sample $\mathrm{k}$.

- If the process proportions are known, then a common statistical task which is the Pearson goodness-of-fit statistic is applied and defined as follows (Equation 2):

$$
Z_{i}^{2}=\sum_{j=1}^{t} \frac{\left(X_{i j}-n_{i} \pi_{j}\right)^{2}}{n_{i} \pi_{j}}
$$

where $X_{i j}$ is the number of items of category $j$ in sample $i, n_{i}$ is the size of sample $i$ and $\pi_{j}$ is the proportion of category $\mathbf{j}, Z_{i}^{2} \rightarrow \chi^{2}(q-1)$, where $\mathrm{q}$ is the number of categories of quality.

The upper control limit for the CSCC is expressed as a level of percentile of the chisquare distribution as follows (Equation 3):

$U C L=\chi_{\alpha}^{2}(q-1)$

where $\alpha$ is the significance level.

Table 1. Marcucci's Example.

\begin{tabular}{ccccccc}
\hline Time & Conforming & $\begin{array}{c}\text { Non-conforming } \\
\text { Type A }\end{array}$ & $\begin{array}{c}\text { Non-conforming } \\
\text { Type B }\end{array}$ & Total & $Z i^{2}$ & $Y i^{2}$ \\
\hline 1 & 242 & 8 & 4 & 254 & 0.25 & 0.23 \\
\hline 2 & 199 & 5 & 3 & 207 & 0.58 & 0.81 \\
\hline 3 & 228 & 10 & 5 & 243 & 1.05 & 0.78 \\
\hline 4 & 193 & 5 & 3 & 201 & 0.46 & 0.65 \\
\hline 5 & 214 & 15 & 3 & 232 & 10.05 & 3.11 \\
\hline 6 & 132 & 4 & 2 & 138 & 0.22 & 0.35 \\
\hline 7 & 206 & 7 & 5 & 218 & 0.13 & 0.2 \\
\hline 8 & 146 & 5 & 4 & 155 & 0.3 & 0.79 \\
\hline 9 & 207 & 7 & 7 & 221 & 1.57 & 4.28 \\
\hline 10 & 174 & 24 & 8 & 206 & 57.44 & 75.93 \\
\hline 11 & 223 & 12 & 10 & 245 & 8.66 & 26.09 \\
\hline 12 & 204 & 12 & 5 & 221 & 4.59 & 2.34 \\
\hline 13 & 196 & 8 & 8 & 212 & 3.9 & 14.79 \\
\hline 14 & 225 & 10 & 10 & 245 & 6.52 & 24.67 \\
\hline 15 & 225 & 7 & 5 & 237 & 0.02 & 0.02 \\
\hline 16 & 141 & 2 & 5 & 148 & 2.75 & 12.83 \\
\hline
\end{tabular}


Consequently, the UCL control limit for the Marcucci's example is equal to 5:99. The CSCC provides an out-of-control signal when a single plotted point exceeds UCL. Therefore, it relies only on a single value to take decision and it is relatively insensitive to small process shift. Hence if we consider the additional data given in Table 2, we can notice that it is difficult to interpret the results. Both observations are significantly outside the control limit with a false alarm rate of 0.05 as used by Marcucci (1985). For observation 18, though we do not have non-conforming items, the process detects an out-of-control signal.

Table 2. Additional data for Marcucci Example.

\begin{tabular}{cccccc}
\hline Time & Conforming & $\begin{array}{c}\text { Non- } \\
\text { conforming } \\
\text { Type A }\end{array}$ & $\begin{array}{c}\text { Non- } \\
\text { conforming } \\
\text { Type B }\end{array}$ & Total & $Z_{i}^{2}$ \\
\hline 17 & 200 & 10 & 50 & 260 & 395.5 \\
\hline 18 & 260 & 0 & 0 & 260 & 13.7 \\
\hline
\end{tabular}

Consequently, we can explain that the statistical test used by Marcucci, i.e., the Pearson statistic, is unable to detect whether we actually have a process deterioration or a process improvement. Then, as a conclusion, for the CSCC, an out-of control situation does not specify if it was a process deterioration or a process improvement. For this reason, a WSCC is proposed with different weighting categories in order to enable an accelerated disclosure of a control situation after a shift due to a deterioration of quality and on the other hand, decelerate an out-of-control situation after a shift due to a quality improvement. Furthermore, in comparison with Marcucci's method, the new procedure provides an accurate and easier way to interpret several signals. In other words, the WSCC allows a faster detection of an out-of control situation in the case of a quality deterioration, however, an out-of control situation is not quickly detected in the case of a quality improvement. Taleb \& Limam (2002) proposed another approach which is based on membership functions, all categories are represented with only one representative value according to fuzzy theories and fuzzy sets. Fuzzy sets are composed by objects with different degrees of membership that varies in a range between 0 and 1, membership functions are associated to each object and their values come from the fact that it is impossible to precisely identify the class to which belongs objects in the set; the vagueness; the lack of clearly defined criteria for classifying and the presence of random variables makes it necessary to resort to fuzzy theory and membership functions to solve problem of identification. The classic function takes only 2 values 0 and 1 which indicates the certainty of the class that owns the object. If the value assigned is 0 so object does not belong to the set, else (value $=1$ ) it is certain that the object is part of the set. However, the membership function can cover a multitude of values between 0 and 1 according to the degree of membership of an object to a class. If the value is different from 1 or 0 , so we are doubting about the membership of the object to the class. The major difference between a characteristic function and a membership function is that the first is unique while the second is infinite and can generate an infinite number of membership functions. In addition, it consists only of weighting all the categories according to their proportions into a single representative value which, using fuzzy operations, makes it possible to derive a representative value capable of emphasizing the improvement or the deterioration of the quality. However, fuzzy theory is based on uncertainty and hesitation in the assignment due to human subjectivity and the shape of the membership function will change. Fuzzy sets are then drawn with intersection areas between categories. This problem of undefined limits makes better to privilege the probability theory and propose 
our new approach. In the following section, a new approach that offers an easier way to interpret an out-of-control signal is presented. The new method is called the Weighted Sum of Chi-squares method (WSCC).

\section{The Weighted Sum of the Chi-square Control Chart (WSCC)}

The WSCC consists in assigning a weight for each category as defined in the below Statistic (Equation 4):

$$
Y_{i}^{2}=\sum_{j=1}^{q} W_{j} Z_{i, j}^{2}
$$

In the test statistic, $\mathrm{Wj}$ is an appropriate way to determine the weights and shows a new method in order to find the relative weights of each category. This weight could be defined according to the following Equation 5:

$W_{j}=e^{\left(j-\frac{q}{2}-1\right)\left(\frac{X_{j}-n p_{j}}{\sqrt{n p_{j}}}\right)}$

Where:

$q$ is the number of categories.

$\mathrm{j}=1 ; \ldots ; \mathrm{q}$.

$\mathrm{n}$ is the sample size.

$\mathrm{p}_{\mathrm{j}}$ is the proportion for each category.

for instance, if the number of categories is equal to $q=4$, we will find the following results

$j=1 \rightarrow j-\frac{q}{2}-1=-2$

$j=2 \rightarrow j-\frac{q}{2}-1=-1$

$j=3 \rightarrow j-\frac{q}{2}-1=0$

$j=4 \rightarrow j-\frac{q}{2}-1=1$

on the other side of the weighting formula, and for the baseline proportions $(p=[0: 6 ; 0: 25$; $0: 1 ; 0: 05])$ and the same number of categories $(q=4)$, we find for $n=1000$ observation the following results:

- $p=[0.6 ; 0.25 ; 0.1 ; 0.05] \rightarrow$ we have 600 for $C_{1}, 250$ for $C_{2}, 100$ for $C_{3}$ and 50 for $\mathrm{C}_{4}$ 
- if $\mathrm{X}_{\mathrm{j}}$ gives 608 for $\mathrm{C}_{1}$, then $\left(\frac{X_{j}-n p_{j}}{\sqrt{n p_{j}}}\right)=0.32$

- if $\mathrm{X}_{\mathrm{j}}$ gives 580 for $\mathrm{C}_{1}$, then $\left(\frac{X_{j}-n p_{j}}{\sqrt{n p_{j}}}\right)=-0.81$

Table 3. An Illustration of the Effectiveness of CSCC.

\begin{tabular}{|c|c|c|c|c|c|c|c|c|}
\hline & $C_{1}$ & & $\ldots$ & & $C_{q}$ & & & \\
\hline$j-\frac{q}{2}-1$ & $\frac{X_{j}-n p_{j}}{\sqrt{n p_{j}}}$ & $W_{j}$ & $\ldots$ & $j-\frac{q}{2}-1$ & $\left(\frac{X_{j}-n p_{j}}{\sqrt{n p_{j}}}\right)$ & $W_{j}$ & $Y_{i}^{2}$ & \\
\hline - & + & $W_{j} \rightarrow 0$ & $\ldots$ & + & - & $W_{j} \rightarrow 0$ & $\Delta$ & $\begin{array}{c}\text { In } \\
\text { control }\end{array}$ \\
\hline- & - & $W_{j} \rightarrow+\infty$ & $\ldots$ & + & + & $W_{j} \rightarrow+\infty$ & 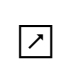 & $\begin{array}{l}\text { Out of } \\
\text { control }\end{array}$ \\
\hline
\end{tabular}

- if $\mathrm{X}_{\mathbf{j}}$ gives 56 for $\mathrm{C}_{4}$, then $\left(\frac{X_{j}-n p_{j}}{\sqrt{n p_{j}}}\right)=0.84$

- if $\mathrm{X}_{\mathrm{j}}$ gives 48 for $\mathrm{C}_{4}$, then $\left(\frac{X_{j}-n p_{j}}{\sqrt{n p_{j}}}\right)=-0.28$

The aim of the new approach is to improve the sensitivity of $Y_{i}^{2}$ only on the shift affecting the worst categories, which leads to improve the sensitivity of the chart in detecting the process deterioration. Table 3 is provided in order to better assimilate the effectiveness of the WSCC. With $C_{1}$ and $C_{q}$ represent respectively the best and the worst categories. In fact, in case of quality improvement, i.e, the number of observations in best category $\left(C_{1}\right)$ increased, the corresponding weigh decreases, hence the process is in control. However, in case of quality deterioration, i.e, the number of observations in worst category $\left(\mathrm{C}_{\mathrm{q}}\right)$ increased, the corresponding weigh increases, hence the process is out-of control. A lot of researches proved that the density function for the distribution of a weighted sum of independent chi-square random variables cannot be represented by elementary analytic functions. However, in many cases, the feasibility of approximating the distribution of $Y_{i}^{2}$ by a gamma distribution is proven feasible (Equation 6,7 and 8 ), the first two moments are equal to the first two moments of $Y_{i}^{2}$ (Feiveson \& Delaney, 1968). Thus:

$G_{Y_{i}^{2}}(x)=\int_{0}^{x} \frac{\alpha^{\lambda}}{\Gamma(\lambda)} e^{-\alpha t} t^{\lambda-1} d t$

With: 
$\alpha=\left(\frac{1}{2}\right)\left(\frac{\sum W_{i}}{\sum W_{i}^{2}}\right)$

$\lambda=\left(\frac{1}{2}\right)\left(\frac{\left(\sum W_{i}\right)^{2}}{\sum W_{i}^{2}}\right)$

Consequently, the UCL is equal to a level of percentile of the Gamma distribution expressed as follows (Equation 9):

$U C L=\Gamma(p, \alpha, \lambda)$

with $\mathrm{p}$ is the false alarm rate. However, determining the statistical test distribution of $Y_{i}^{2}$ with the new weight $W_{j}$ is not an easy task due to the unequally weights, and we are not certain if it follows Gamma distribution or not, future research may focus on this distribution. Hence, in this paper, the UCL is computed using Simulation.

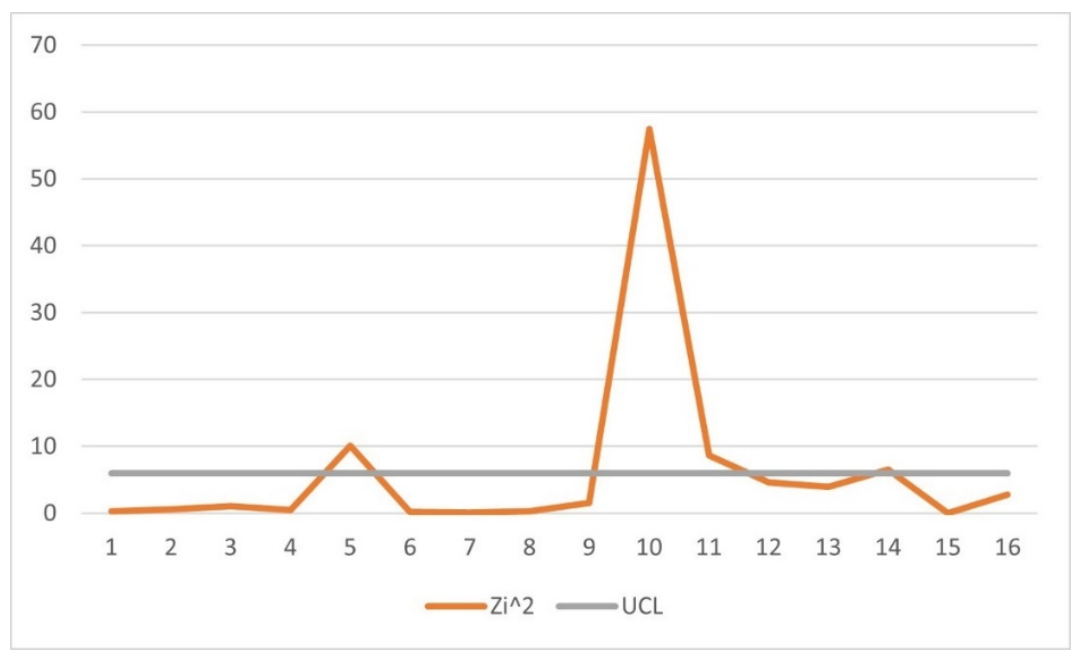

Figure 1. Chi-Square-Chart.

\section{Experimental study}

To illustrate the application of the proposed WSCC and the interpretation of its out-ofcontrol signal, The Marcucci example given in Table 1 is considered. In our experimental study, some assumptions have been introduced; we set false alarm rate on $\alpha=0.05$. The corresponding upper control limit for the WSCC is calculated using simulation and it is equal to $U C L=5.02$. Moreover, large sample sizes were investigated for this study, i.e $n=100 ; 300 ; 500 ; 1000$. Then, for the chi-square chart, the $U C L=5.99$ and it's equal to the percentile level of the chi-square distribution. Figure 1 and Figure 2 represent the resulting CSCC and the WSCC: As highlighted on Figure 1 and Figure 2, 4 samples are out-of control for the CSCC however 5 samples are out-of control for the WSCC. A close examination of the data related to those samples, indicated that despite sample 5 represents an improvement of the quality, however the CSCC consider it as out of control, 
but the proposed WSCC was able to differentiate that it was an improvement of the quality and consequently interpreted the signal as in-control. On the other side, if we analyze the data related to sample 13, we found out that this sample represents a deterioration of the quality. Consequently, the WSCC has succeeded in interpreting it as an out-of control situation. After this analysis, we can conclude, as a general rule, that the WSCC outperforms the CSCC in differentiating between the improvement and the deterioration of the quality.

The sensitivity analysis is determined in terms of the ARL and SDRL. In the field of Statistical Process Control, the random variable generally used to evaluate the performance of a control chart (based on the $T_{i}$ statistic) is the Run Length defined by Equation 10:

$$
R L=\inf \left\{i=1,2, \ldots \mid T_{i} \notin[L C L, U C L]\right\} .
$$

When possible, it is important to evaluate its probability density function $f_{R L}(I)$, its cumulative distribution function $F_{R L}(I)$, its mean value $A R L=E(R L)$ (Equation 11) and its standard deviation SDRL $=\delta(R L)$ (Standard-deviation Run Length), (Equation 12). Moreover, the number of samples needed to report an out of control situation (which equals the length of the sequence) is a geometric random variable $R L$ (the support of the random variable $\Omega(R L)=(1 ; 2 ; 3 ; \ldots ; \infty)$. The $A R L$ of this geometric variable $R L$ with parameter $p$ is is given by its first moment.

$E(R L)=\frac{1}{p}=A R L$

The variance of the geometric run length variable $R L$ is

$V(R L)=\frac{1-p}{p^{2}}=(1-p) A R L^{2}$

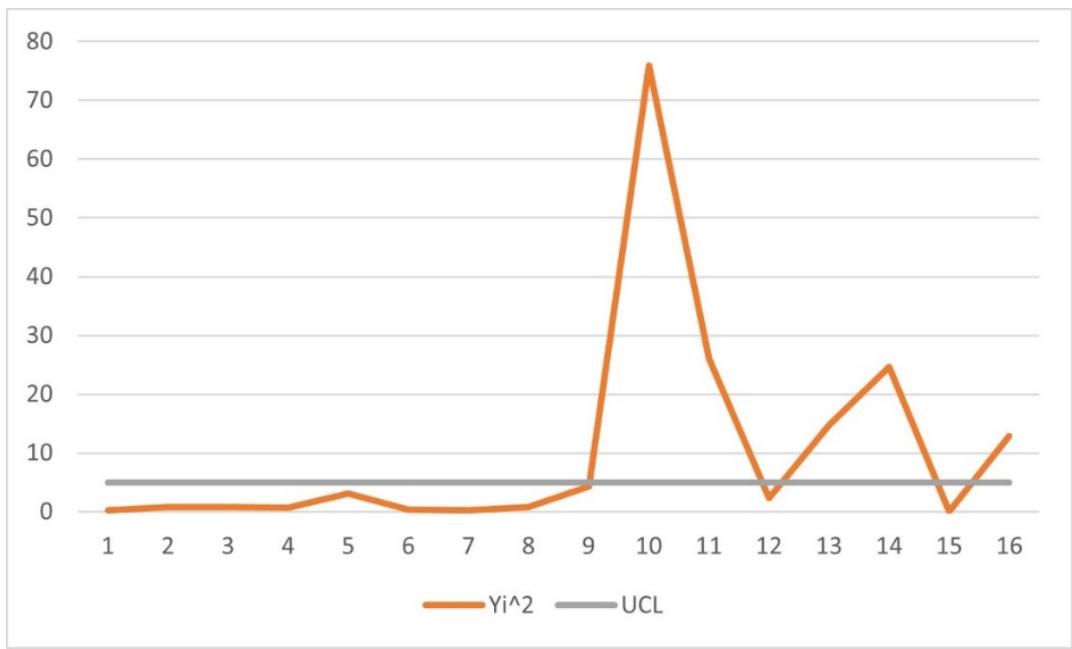

Figure 2. Weighted-Chi-square-Chart 
Table 4. ARL for Known Proportions with $q=5$ and $n=1000$.

\begin{tabular}{|c|c|c|c|c|}
\hline \multirow{2}{*}{ Baseline proportions } & \multicolumn{4}{|c|}{$n=1000$} \\
\hline & \multicolumn{4}{|c|}{$q=5$} \\
\hline \multirow{4}{*}{$P=\left[\begin{array}{lllll}0.50 & 0.30 & 0.10 & 0.07 & 0.03\end{array}\right]$} & $\mathrm{UCL}\left(Z_{i}^{2}\right)$ & $\operatorname{SDRL}\left(Z_{i}^{2}\right)$ & $\mathrm{UCL}\left(Y_{i}^{2}\right)$ & $\operatorname{SDRL}\left(Y_{i}^{2}\right)$ \\
\hline & 9.487729 & 19.1013 & 91.036737 & 19.453656 \\
\hline & $\operatorname{ARL}\left(Z_{i}^{2}\right)$ & & $\operatorname{ARL}\left(Y_{i}^{2}\right)$ & \\
\hline & 19.607843 & & 19.96008 & \\
\hline Improvement & $\operatorname{ARL}\left(Z_{i}^{2}\right)$ & $\operatorname{SDRL}\left(Z_{i}^{2}\right)$ & $\operatorname{ARL}\left(Y_{i}^{2}\right)$ & $\operatorname{SDRL}\left(Y_{i}^{2}\right)$ \\
\hline$P=\left[\begin{array}{llllll}0.52 & 0.30 & 0.10 & 0.07 & 0.01\end{array}\right]$ & 1.0486577 & 0.2258877 & 136.9863 & 136.48538 \\
\hline$P=\left[\begin{array}{llllll}0.55 & 0.30 & 0.10 & 0.02 & 0.03\end{array}\right]$ & 1 & 0 & 35.460993 & 34.957417 \\
\hline$P=\left[\begin{array}{llllll}0.55 & 0.30 & 0.05 & 0.07 & 0.03\end{array}\right]$ & 1.0002 & 0.0141435 & 1.0316723 & 0.1807635 \\
\hline$P=\left[\begin{array}{llllll}0.58 & 0.22 & 0.10 & 0.07 & 0.03\end{array}\right]$ & 1.0007005 & 0.0264762 & 1.0001 & 0.0100005 \\
\hline$P=\left[\begin{array}{lllll}0.60 & 0.27 & 0.09 & 0.03 & 0.01\end{array}\right]$ & 1 & 0.0264762 & 2.7785496 & 2.2230133 \\
\hline Deterioration & $\operatorname{ARL}\left(Z_{i}^{2}\right)$ & $\operatorname{SDRL}\left(Z_{i}^{2}\right)$ & $\operatorname{ARL}\left(Y_{i}^{2}\right)$ & $\operatorname{SDRL}\left(Y_{i}^{2}\right)$ \\
\hline$P=\left[\begin{array}{llllll}0.48 & 0.30 & 0.10 & 0.07 & 0.05\end{array}\right]$ & 1.2227929 & 0.5219479 & 1.0887316 & 0.3108133 \\
\hline$P=\left[\begin{array}{llllll}0.43 & 0.30 & 0.17 & 0.07 & 0.03\end{array}\right]$ & 1 & 0.0283062 & 1.0053282 & 0.0731887 \\
\hline$P=\left[\begin{array}{llllll}0.43 & 0.37 & 0.10 & 0.07 & 0.03\end{array}\right]$ & 1.0091836 & 0.0962701 & 1.0085729 & 0.0929860 \\
\hline$P=\left[\begin{array}{llllll}0.40 & 0.32 & 0.12 & 0.10 & 0.08\end{array}\right]$ & 1 & 0 & 1 & 0 \\
\hline
\end{tabular}

Hence the standard deviation (SD) of the run length is

$S D(R L)=\sqrt{1-p} \quad \mathrm{ARL}$

\section{Sensitivity analysis}

In this section we summarize the results of a simulation study comparing the ARL and SDRL performance of the previously discussed CSCC and WSCC where the sample sizes are fixed, without loss of generality at $n=100,300,500,1000$, and a fixed number of categories at $\mathrm{q}=3,4,5$ (see from Table 4 to Table 15). This study provided a baseline information about the performance of the weighted sum of chi-square approach. In this simulation study, 10.000 samples are used to estimate each ARL and SDRL values. The Simulation study was done on two phases as below:

- Phase I

- Step1: Generate 10:000 Samples with fixed size $n=100,300,500,1000$, using known proportions $p_{0}=\left[p_{01} ; p_{02} ; \ldots ; p_{0 q}\right]$ with $p_{0 j}$ is a specified proportion associated with each category $\mathrm{j}=1 ; \ldots ; \mathrm{q}$.

- Step 2: Calculate for each sample the corresponding $\mathrm{Yi}^{2}$ and $\mathrm{Zi}^{2}$

- Step 3: Calculate the UCLo using a fixed Type I error for each chart.

- Phase II

- Step 4: For fixed shifts of proportions vectors, generate 10:000 samples and calculate the corresponding $\mathrm{Yi}^{2}$ and $\mathrm{Zi}^{2}$

- Step 5: Calculate the number of samples plotted outside the UCL $\mathrm{L}_{0}$ for both charts.

- Step 6: Calculate the ARL and SDRL for each chart.

The following remarks can be deduced as conclusions from Table 4 to Table 15 below:

- Process Improvement: 
As the number of categories increases, the values of $\operatorname{ARL}\left(Y_{i}^{2}\right)$ and $\operatorname{SDRL}\left(Y_{i}^{2}\right)$ increase:

$\mathrm{P}=[0.52,0.30,0.10,0.07,0.01] \rightarrow \operatorname{ARL}\left(Y_{i}^{2}\right)=136.9863$ and $\operatorname{SDRL}\left(Y_{i}^{2}\right)=136.48538$,

$\mathrm{P}=[0.64,0.25,0.10,0.01] \rightarrow \operatorname{ARL}\left(Y_{i}^{2}\right)=98.039216$ and $\operatorname{SDRL}\left(Y_{i}^{2}\right)=97.537934$,

$\mathrm{P}=[0.75,0.20,0.05] \rightarrow \operatorname{ARL}\left(Y_{i}^{2}\right)=67.567568$ and $\operatorname{SDRL}\left(Y_{i}^{2}\right)=67.065704$,

As the sample size increases, the values of $\operatorname{ARL}\left(Y_{i}^{2}\right)$ and $\operatorname{SDRL}\left(Y_{i}^{2}\right)$ increase, for instance:

$$
\begin{aligned}
& \mathrm{n}=100 \rightarrow \operatorname{ARL}\left(Y_{i}^{2}\right)=99.009901 \text { and } \operatorname{SDRL}\left(Y_{i}^{2}\right)=98.508632 \\
& \mathrm{n}=300 \rightarrow \operatorname{ARL}\left(Y_{i}^{2}\right)=21.716467 \text { and } \operatorname{SDRL}\left(Y_{i}^{2}\right)=19.96008 \\
& \mathrm{n}=500 \rightarrow \operatorname{ARL}\left(Y_{i}^{2}\right)=112.35955 \text { and } \operatorname{SDRL}\left(Y_{i}^{2}\right)=111.85843 \\
& \mathrm{n}=1000 \rightarrow \operatorname{ARL}\left(Y_{i}^{2}\right)=136.9863 \text { and } \operatorname{SDRL}\left(Y_{i}^{2}\right)=136.48538,
\end{aligned}
$$

As the proportion in the best category increases, the $\operatorname{ARL}\left(Y_{i}^{2}\right)$ exceeds the $\operatorname{ARL}\left(Z_{i}^{2}\right)$ : $P=[0.52,0.30,0.10,0.07,0.01]$ the $A R L$ of the CSCC is equal to 1.0486577 however the ARL of the WSCC is equal to 136.9863 .

- Process Deterioration:

As the sample size increases, the values of $\operatorname{ARL}\left(Y_{i}^{2}\right)$ and $\operatorname{SDRL}\left(Y_{i}^{2}\right)$ decreases:

$$
\begin{aligned}
& \mathrm{n}=100 \rightarrow \operatorname{ARL}\left(Y_{i}^{2}\right)=6.7204301 \text { and } \operatorname{SDRL}\left(Y_{i}^{2}\right)=6.2003025 \\
& \mathrm{n}=300 \rightarrow \operatorname{ARL}\left(Y_{i}^{2}\right)=3.8774719 \text { and } \operatorname{SDRL}\left(Y_{i}^{2}\right)=3.3402569 \\
& \mathrm{n}=500 \rightarrow \operatorname{ARL}\left(Y_{i}^{2}\right)=2.6226069 \text { and } \operatorname{SDRL}\left(Y_{i}^{2}\right)=2.0628766 \\
& \mathrm{n}=1000 \rightarrow \operatorname{ARL}\left(Y_{i}^{2}\right)=1.6697278 \text { and } \operatorname{SDRL}\left(Y_{i}^{2}\right)=1.0574796,
\end{aligned}
$$

\begin{tabular}{|c|c|c|c|c|}
\hline \multirow{2}{*}{ Baseline proportions } & \multicolumn{4}{|c|}{$n=1000$} \\
\hline & \multicolumn{4}{|c|}{$q=4$} \\
\hline \multirow{4}{*}{$P=\left[\begin{array}{llll}0.60 & 0.25 & 0.10 & 0.05\end{array}\right]$} & $\operatorname{UCL}\left(Z_{i}^{2}\right)$ & $\operatorname{SDRL}\left(Z_{i}^{2}\right)$ & $\mathrm{UCL}\left(Y_{i}^{2}\right)$ & $\operatorname{SDRL}\left(Y_{i}^{2}\right)$ \\
\hline & 7.8147279 & 20.327185 & 31.619325 & 19.453656 \\
\hline & $\operatorname{ARL}\left(Z_{i}^{2}\right)$ & & $\operatorname{ARL}\left(Y_{i}^{2}\right)$ & \\
\hline & 20.833333 & & 19.96008 & \\
\hline Improvement & $\operatorname{ARL}\left(Z_{i}^{2}\right)$ & $\operatorname{SDRL}\left(Z_{i}^{2}\right)$ & $\operatorname{ARL}\left(Y_{i}^{2}\right)$ & $\operatorname{SDRL}\left(Y_{i}^{2}\right)$ \\
\hline$P=\left[\begin{array}{llll}0.64 & 0.25 & 0.10 & 0.01\end{array}\right]$ & 1 & 0 & 98.039216 & 97.537934 \\
\hline$P=\left[\begin{array}{lllll}0.65 & 0.25 & 0.05 & 0.05\end{array}\right]$ & 1.0002 & 0.0141435 & 2.9664788 & 2.4152676 \\
\hline$P=\left[\begin{array}{llll}0.69 & 0.25 & 0.05 & 0.01\end{array}\right]$ & 1 & 0 & 3.866976 & 3.3296437 \\
\hline$P=\left[\begin{array}{lllll}0.70 & 0.15 & 0.10 & 0.05\end{array}\right]$ & 1 & 0 & 1 & 0 \\
\hline$P=\left[\begin{array}{llll}0.75 & 0.15 & 0.05 & 0.05\end{array}\right]$ & 1 & 0 & 1 & 0 \\
\hline Deterioration & $\operatorname{ARL}\left(Z_{i}^{2}\right)$ & $\operatorname{SDRL}\left(Z_{i}^{2}\right)$ & $\operatorname{ARL}\left(Y_{i}^{2}\right)$ & $\operatorname{SDRL}\left(Y_{i}^{2}\right)$ \\
\hline$P=\left[\begin{array}{llll}0.55 & 0.25 & 0.10 & 0.10\end{array}\right]$ & 1 & 0 & 1 & 0 \\
\hline$P=\left[\begin{array}{llll}0.52 & 0.25 & 0.15 & 0.08\end{array}\right]$ & 1 & 0 & 1 & 0 \\
\hline$P=\left[\begin{array}{lllll}0.50 & 0.35 & 0.10 & 0.05\end{array}\right]$ & 1 & 0 & 1.0001 & 0.0100005 \\
\hline$P=\left[\begin{array}{lllll}0.50 & 0.30 & 0.15 & 0.05\end{array}\right]$ & 1 & 0 & 1 & 0 \\
\hline
\end{tabular}

As the number of categories increases, the values of $\operatorname{ARL}\left(Y_{i}^{2}\right)$ and $\operatorname{SDRL}\left(Y_{i}^{2}\right)$ decreases:

It is interesting to note that in most samples, the WSCC outperforms the CSCC in detecting a process deterioration comparing to CSCC.

Table 5. ARL for Known Proportions with $q=4$ and $n=1000$. 
Table 6. ARL for Known Proportions with $q=3$ and $n=1000$.

\begin{tabular}{|c|c|c|c|c|}
\hline \multirow{2}{*}{ Baseline proportions } & \multicolumn{4}{|c|}{$n=1000$} \\
\hline & & & $q=3$ & \\
\hline \multirow{4}{*}{$P=\left[\begin{array}{lll}0.7 & 0.2 & 0.1\end{array}\right]$} & $\mathrm{UCL}\left(Z_{i}^{2}\right)$ & $\operatorname{SDRL}\left(Z_{i}^{2}\right)$ & $\mathrm{UCL}\left(Y_{i}^{2}\right)$ & $\operatorname{SDRL}\left(Y_{i}^{2}\right)$ \\
\hline & 5.9914646 & 19.374265 & 11.225403 & \\
\hline & $\operatorname{ARL}\left(Z_{i}^{2}\right)$ & & $\operatorname{ARL}\left(Y_{i}^{2}\right)$ & \\
\hline & 19.880716 & & 1.96008 & \\
\hline Improvement & $\operatorname{ARL}\left(Z_{i}^{2}\right)$ & $\operatorname{SDRL}\left(Z_{i}^{2}\right)$ & $\operatorname{ARL}\left(Y_{i}^{2}\right)$ & $\operatorname{SDRL}\left(Y_{i}^{2}\right)$ \\
\hline$P=\left[\begin{array}{llll}0.75 & 0.20 & 0.05\end{array}\right]$ & 1 & 0 & 67.567568 & 67.065704 \\
\hline$P=\left[\begin{array}{llll}0.75 & 0.15 & 0.10\end{array}\right]$ & 1.0306091 & 0.1776120 & 1.0291242 & 0.1731254 \\
\hline$P=\left[\begin{array}{lll}0.76 & 0.20 & 0.04\end{array}\right]$ & 1 & 0 & 67.567568 & 67.065704 \\
\hline$P=\left[\begin{array}{lll}0.78 & 0.16 & 0.06\end{array}\right]$ & 1.0001 & 0.0100005 & 1.1419436 & 0.4026060 \\
\hline$P=\left[\begin{array}{lll}0.80 & 0.10 & 0.10\end{array}\right]$ & 1 & 0 & 1 & 0 \\
\hline Deterioration & $\operatorname{ARL}\left(Z_{i}^{2}\right)$ & $\operatorname{SDRL}\left(Z_{i}^{2}\right)$ & $\operatorname{ARL}\left(Y_{i}^{2}\right)$ & $\operatorname{SDRL}\left(Y_{i}^{2}\right)$ \\
\hline$P=\left[\begin{array}{lll}0.68 & 0.20 & 0.12\end{array}\right]$ & 2.1838829 & 1.6079371 & 1.6697278 & 1.0574796 \\
\hline$P=\left[\begin{array}{lll}0.65 & 0.23 & 0.12\end{array}\right]$ & 1.1384335 & 0.3969853 & 1.0887316 & 0.3108133 \\
\hline$P=\left[\begin{array}{llll}0.60 & 0.20 & 0.20\end{array}\right]$ & 1 & 0 & 1 & 0 \\
\hline$P=\left[\begin{array}{lll}0.55 & 0.25 & 0.20\end{array}\right]$ & 1 & 0 & 1 & 0 \\
\hline
\end{tabular}

Table 7. ARL for Known Proportions with $q=5$ and $n=500$.

\begin{tabular}{|c|c|c|c|c|}
\hline \multirow{2}{*}{ Baseline proportions } & \multicolumn{4}{|c|}{$n=500$} \\
\hline & & & $q=5$ & \\
\hline \multirow{4}{*}{$P=\left[\begin{array}{lllll}0.50 & 0.30 & 0.10 & 0.07 & 0.03\end{array}\right]$} & $\operatorname{UCL}\left(Z_{i}^{2}\right)$ & $\operatorname{SDRL}\left(Z_{i}^{2}\right)$ & $\mathrm{UCL}\left(Y_{i}^{2}\right)$ & $\operatorname{SDRL}\left(Y_{i}^{2}\right)$ \\
\hline & 9.487729 & 19.1013 & 95.113769 & \\
\hline & $\operatorname{ARL}\left(Z_{i}^{2}\right)$ & & $\operatorname{ARL}\left(Y_{i}^{2}\right)$ & \\
\hline & 19.607843 & & 19.96008 & \\
\hline Improvement & $\operatorname{ARL}\left(Z_{i}^{2}\right)$ & $\operatorname{SDRL}\left(Z_{i}^{2}\right)$ & $\operatorname{ARL}\left(Y_{i}^{2}\right)$ & $\operatorname{SDRL}\left(Y_{i}^{2}\right)$ \\
\hline$P=\left[\begin{array}{lllll}0.52 & 0.30 & 0.10 & 0.07 & 0.01\end{array}\right]$ & 1.7969452 & 1.19669 & 112.35955 & 111.85843 \\
\hline$P=\left[\begin{array}{llllll}0.55 & 0.30 & 0.10 & 0.02 & 0.03\end{array}\right]$ & 1.0031096 & 0.0558504 & 27.624309 & 27.1197 \\
\hline$P=\left[\begin{array}{lllll}0.55 & 0.30 & 0.05 & 0.07 & 0.03\end{array}\right]$ & 1.0654166 & 0.2639999 & 2.2727273 & 1.7007534 \\
\hline$P=\left[\begin{array}{lllll}0.58 & 0.22 & 0.10 & 0.07 & 0.03\end{array}\right]$ & 1.0659844 & 0.2652138 & 1.0539629 & 0.2384846 \\
\hline$P=\left[\begin{array}{lllll}0.60 & 0.27 & 0.09 & 0.03 & 0.01\end{array}\right]$ & 1.00040020 & 0.0200090 & 6.6269052 & 6.1064693 \\
\hline Deterioration & $\operatorname{ARL}\left(Z_{i}^{2}\right)$ & $\operatorname{SDRL}\left(Z_{i}^{2}\right)$ & $\operatorname{ARL}\left(Y_{i}^{2}\right)$ & $\operatorname{SDRL}\left(Y_{i}^{2}\right)$ \\
\hline$P=\left[\begin{array}{lllll}0.48 & 0.30 & 0.10 & 0.07 & 0.05\end{array}\right]$ & 1.866368 & 1.271598 & 1.406272 & 0.7558630 \\
\hline$P=\left[\begin{array}{lllll}0.43 & 0.30 & 0.17 & 0.07 & 0.03\end{array}\right]$ & 1.0094892 & 0.0978736 & 1.1591515 & 0.4295122 \\
\hline$P=\left[\begin{array}{lllll}0.43 & 0.37 & 0.10 & 0.07 & 0.03\end{array}\right]$ & 1.1978917 & 0.4868807 & 1.1676787 & 0.4424871 \\
\hline$P=\left[\begin{array}{lllll}0.40 & 0.32 & 0.12 & 0.10 & 0.08\end{array}\right]$ & 1.0025063 & 0.0501257 & 1.0015023 & 0.4424871 \\
\hline
\end{tabular}

Table 8. ARL for Known Proportions with $q=4$ and $n=500$.

\begin{tabular}{|c|c|c|c|c|}
\hline \multirow{2}{*}{ Baseline proportions } & \multicolumn{4}{|c|}{$\mathrm{n}=\mathbf{5 0 0}$} \\
\hline & \multicolumn{4}{|c|}{$q=4$} \\
\hline \multirow{4}{*}{$P=\left[\begin{array}{llll}0.60 & 0.25 & 0.10 & 0.05\end{array}\right]$} & $\mathrm{UCL}\left(Z_{i}^{2}\right)$ & $\operatorname{SDRL}\left(Z_{i}^{2}\right)$ & $\mathrm{UCL}\left(Y_{i}^{2}\right)$ & $\operatorname{SDRL}\left(Y_{i}^{2}\right)$ \\
\hline & 7.8147279 & 19.334736 & 31.426705 & 19.453656 \\
\hline & $\operatorname{ARL}\left(Z_{i}^{2}\right)$ & & $\operatorname{ARL}\left(Y_{i}^{2}\right)$ & \\
\hline & 19.8412 & & 19.96008 & \\
\hline Improvement & $\operatorname{ARL}\left(Z_{i}^{2}\right)$ & $\operatorname{SDRL}\left(Z_{i}^{2}\right)$ & $\operatorname{ARL}\left(Y_{i}^{2}\right)$ & $\operatorname{SDRL}\left(Y_{i}^{2}\right)$ \\
\hline
\end{tabular}


Table 8. Continued...

\begin{tabular}{|c|c|c|c|c|}
\hline \multirow{3}{*}{ 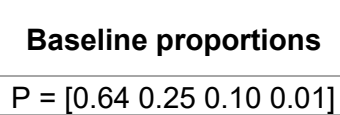 } & \multicolumn{4}{|c|}{$n=500$} \\
\hline & \multicolumn{4}{|c|}{$q=4$} \\
\hline & .0017029 & 0.0413013 & 103.09278 & 102.59156 \\
\hline$P=\left[\begin{array}{llll}0.65 & 0.25 & 0.05 & 0.05\end{array}\right]$ & 1.0446046 & 0.2158568 & 15.151515 & 14.642981 \\
\hline$P=\left[\begin{array}{llll}0.69 & 0.25 & 0.05 & 0.01\end{array}\right]$ & 1 & 0 & 46.296296 & 45.793566 \\
\hline$P=\left[\begin{array}{lllll}0.70 & 0.15 & 0.10 & 0.05\end{array}\right]$ & 1.0007005 & 0.0264762 & 1.0003001 & 0.0173260 \\
\hline$P=\left[\begin{array}{llll}0.75 & 0.15 & 0.05 & 0.05\end{array}\right]$ & 1 & 0 & 1.0001 & 0.0100005 \\
\hline Deterioration & $\operatorname{ARL}\left(Z_{i}^{2}\right)$ & $\operatorname{SDRL}\left(Z_{i}^{2}\right)$ & $\operatorname{ARL}\left(Y_{i}^{2}\right)$ & $\operatorname{SDRL}\left(Y_{i}^{2}\right)$ \\
\hline$P=\left[\begin{array}{lllll}0.55 & 0.25 & 0.10 & 0.10\end{array}\right]$ & 1.021868 & 0.1494865 & 1.0060362 & 0.0779271 \\
\hline$P=\left[\begin{array}{llll}0.52 & 0.25 & 0.15 & 0.08\end{array}\right]$ & 1.0092854 & 0.0968071 & 1.0131712 & 0.1155192 \\
\hline$P=\left[\begin{array}{llll}0.50 & 0.35 & 0.10 & 0.05\end{array}\right]$ & 1.0034116 & 0.0585085 & 1.0083695 & 0.0918670 \\
\hline$P=\left[\begin{array}{llll}0.50 & 0.30 & 0.15 & 0.05\end{array}\right]$ & 1.0928962 & 0.3186313 & 1.0084712 & 0.0918670 \\
\hline
\end{tabular}

Table 9. ARL for Known Proportions with $q=3$ and $n=500$.

\begin{tabular}{|c|c|c|c|c|}
\hline \multirow{2}{*}{ Baseline proportions } & \multicolumn{4}{|c|}{$n=500$} \\
\hline & & & $=3$ & \\
\hline \multirow{4}{*}{$P=\left[\begin{array}{lll}0.7 & 0.2 & 0.1\end{array}\right]$} & $\operatorname{UCL}\left(Z_{i}^{2}\right)$ & $\operatorname{SDRL}\left(Z_{i}^{2}\right)$ & $\operatorname{UCL}\left(Y_{i}^{2}\right)$ & $\operatorname{SDRL}\left(Y_{i}^{2}\right)$ \\
\hline & 5.9914646 & 20.725393 & 11.48985 & 19.334806 \\
\hline & $\operatorname{ARL}\left(Z_{i}^{2}\right)$ & & $\operatorname{ARL}\left(Y_{i}^{2}\right)$ & \\
\hline & 21.231423 & & 19.84127 & \\
\hline Improvement & $\operatorname{ARL}\left(Z_{i}^{2}\right)$ & $\operatorname{SDRL}\left(Z_{i}^{2}\right)$ & $\operatorname{ARL}\left(Y_{i}^{2}\right)$ & $\operatorname{SDRL}\left(Y_{i}^{2}\right)$ \\
\hline$P=\left[\begin{array}{lll}0.75 & 0.20 & 0.05\end{array}\right]$ & 1.0276436 & 0.1685460 & 63.694268 & 63.19229 \\
\hline$P=\left[\begin{array}{lll}0.75 & 0.15 & 0.10\end{array}\right]$ & 1.3504389 & 0.6879290 & 1.3417416 & 0.6771476 \\
\hline$P=\left[\begin{array}{lll}0.76 & 0.20 & 0.04\end{array}\right]$ & 1.0015023 & 0.0387886 & 64.102564 & 63.600599 \\
\hline$P=\left[\begin{array}{lll}0.78 & 0.16 & 0.06\end{array}\right]$ & 1.0239607 & 0.1566359 & 1.8261505 & 1.2282814 \\
\hline$P=\left[\begin{array}{lll}0.80 & 0.10 & 0.10\end{array}\right]$ & 1 & 0 & 1 & 0 \\
\hline Deterioration & $\operatorname{ARL}\left(Z_{i}^{2}\right)$ & $\operatorname{SDRL}\left(Z_{i}^{2}\right)$ & $\operatorname{ARL}\left(Y_{i}^{2}\right)$ & $\operatorname{SDRL}\left(Y_{i}^{2}\right)$ \\
\hline$P=\left[\begin{array}{lll}0.68 & 0.20 & 0.12\end{array}\right.$ & 3.8109756 & 3.2730046 & 2.6226069 & 2.0628766 \\
\hline$P=\left[\begin{array}{lll}0.65 & 0.23 & 0.12\end{array}\right]$ & 1.69549 & 1.0859081 & 1.4976786 & 0.8633438 \\
\hline$P=\left[\begin{array}{lll}0.60 & 0.20 & 0.20\end{array}\right.$ & 1.0001 & 0.0100005 & 1 & 0 \\
\hline$P=\left[\begin{array}{lll}0.55 & 0.25 & 0.20\end{array}\right]$ & 1 & 0 & 1 & 0 \\
\hline
\end{tabular}

Table 10. ARL for Known Proportions with $q=5$ and $n=300$.

\begin{tabular}{|c|c|c|c|c|}
\hline \multirow{3}{*}{ Baseline proportions } & \multicolumn{4}{|c|}{$\mathrm{n}=\mathbf{3 0 0}$} \\
\hline & & & $q=5$ & \\
\hline & $\mathrm{UCL}\left(Z_{i}^{2}\right)$ & $\operatorname{SDRL}\left(Z_{i}^{2}\right)$ & $\operatorname{UCL}\left(Y_{i}^{2}\right)$ & $\operatorname{SDRL}\left(Y_{i}^{2}\right)$ \\
\hline \multirow{3}{*}{$P=\left[\begin{array}{lllll}0.50 & 0.30 & 0.10 & 0.07 & 0.03\end{array}\right]$} & 9.487729 & 19.453656 & 86.818157 & 19.453656 \\
\hline & $\operatorname{ARL}\left(Z_{i}^{2}\right)$ & & $\operatorname{ARL}\left(Y_{i}^{2}\right)$ & \\
\hline & 20.576132 & & 19.96008 & \\
\hline Improvement & $\operatorname{ARL}\left(Z_{i}^{2}\right)$ & $\operatorname{SDRL}\left(Z_{i}^{2}\right)$ & $\operatorname{ARL}\left(Y_{i}^{2}\right)$ & $\operatorname{SDRL}\left(Y_{i}^{2}\right)$ \\
\hline$P=\left[\begin{array}{lllll}0.52 & 0.30 & 0.10 & 0.07 & 0.01\end{array}\right]$ & 3.7664783 & 19.453655 & 19.96008 & 19.453656 \\
\hline$P=\left[\begin{array}{llllll}0.55 & 0.30 & 0.10 & 0.02 & 0.03\end{array}\right]$ & 1.0954102 & 19.453655 & 34.965035 & 34.461408 \\
\hline$P=\left[\begin{array}{lllll}0.55 & 0.30 & 0.05 & 0.07 & 0.03\end{array}\right]$ & 1.4361626 & 19.453655 & 7.3855244 & 6.8673464 \\
\hline$P=\left[\begin{array}{lllll}0.58 & 0.22 & 0.10 & 0.07 & 0.03\end{array}\right]$ & 1.3640704 & 19.453655 & 1.3390466 & 0.6737946 \\
\hline$P=\left[\begin{array}{lllll}0.60 & 0.27 & 0.09 & 0.03 & 0.01\end{array}\right]$ & 1.0302905 & 19.453655 & 11.600928 & 11.089662 \\
\hline Deterioration & $\operatorname{ARL}\left(Z_{i}^{2}\right)$ & $\operatorname{SDRL}\left(Z_{i}^{2}\right)$ & $\operatorname{ARL}\left(Y_{i}^{2}\right)$ & $\operatorname{SDRL}\left(Y_{i}^{2}\right)$ \\
\hline$P=\left[\begin{array}{lllll}0.48 & 0.30 & 0.10 & 0.07 & 0.05\end{array}\right]$ & 2.7847396 & 19.453655 & 1.9219681 & 1.3311624 \\
\hline$P=\left[\begin{array}{llllll}0.43 & 0.30 & 0.17 & 0.07 & 0.03\end{array}\right]$ & 1.1093854 & 19.453655 & 1.4755792 & 0.8377080 \\
\hline $\mathrm{P}=\left[\begin{array}{lllll}0.43 & 0.37 & 0.10 & 0.07 & 0.03\end{array}\right]$ & 1.6943409 & 19.453655 & 1.5239256 & 0.8935455 \\
\hline$P=\left[\begin{array}{llllll}0.40 & 0.32 & 0.12 & 0.10 & 0.08\end{array}\right]$ & 1.0493179 & 19.453655 & 1.0171905 & 0.1322347 \\
\hline
\end{tabular}


Table 11. ARL for Known Proportions with $q=4$ and $n=300$.

\begin{tabular}{|c|c|c|c|c|}
\hline \multirow{2}{*}{ Baseline proportions } & \multicolumn{4}{|c|}{$n=300$} \\
\hline & & & $q=4$ & \\
\hline \multirow{4}{*}{$P=\left[\begin{array}{llll}0.60 & 0.25 & 0.10 & 0.05\end{array}\right]$} & $\mathrm{UCL}\left(Z_{i}^{2}\right)$ & $\operatorname{SDRL}\left(Z_{i}^{2}\right)$ & $\mathrm{UCL}\left(Y_{i}^{2}\right)$ & $\operatorname{SDRL}\left(Y_{i}^{2}\right)$ \\
\hline & 7.8147279 & 19.178522 & 34.163768 & 19.453656 \\
\hline & $\operatorname{ARL}\left(Z_{i}^{2}\right)$ & & $\operatorname{ARL}\left(Y_{i}^{2}\right)$ & \\
\hline & 19.685039 & & 19.96008 & \\
\hline Improvement & $\operatorname{ARL}\left(Z_{i}^{2}\right)$ & $\operatorname{SDRL}\left(Z_{i}^{2}\right)$ & $\operatorname{ARL}\left(Y_{i}^{2}\right)$ & $\operatorname{SDRL}\left(Y_{i}^{2}\right)$ \\
\hline$P=\left[\begin{array}{llll}0.64 & 0.25 & 0.10 & 0.01\end{array}\right]$ & 1.0980564 & 0.3281333 & 133.33333 & 132.83239 \\
\hline 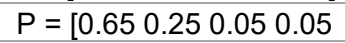 & 1.3299641 & 0.6624503 & 22.421525 & 21.915822 \\
\hline$P=\left[\begin{array}{llll}0.69 & 0.25 & 0.05 & 0.01\end{array}\right]$ & 1.0012014 & 0.0346820 & 80 & 79.498428 \\
\hline$P=\left[\begin{array}{llll}0.70 & 0.15 & 0.10 & 0.05\end{array}\right]$ & 1.0303967 & 0.1769764 & 1.0234367 & 0.1548741 \\
\hline$P=\left[\begin{array}{llll}0.75 & 0.15 & 0.05 & 0.05\end{array}\right]$ & 1.0002 & 0.0141435 & 1.0188487 & 0.1385784 \\
\hline Deterioration & $\operatorname{ARL}\left(Z_{i}^{2}\right)$ & $\operatorname{SDRL}\left(Z_{i}^{2}\right)$ & $\operatorname{ARL}\left(Y_{i}^{2}\right)$ & $\operatorname{SDRL}\left(Y_{i}^{2}\right)$ \\
\hline$P=\left[\begin{array}{llll}0.55 & 0.25 & 0.10 & 0.10\end{array}\right]$ & 1.1405109 & 0.4003176 & 1.0622477 & 0.2571429 \\
\hline$P=\left[\begin{array}{llll}0.52 & 0.25 & 0.15 & 0.08\end{array}\right.$ & 1.0976948 & 0.3274738 & 1.1201972 & 0.3669395 \\
\hline$P=\left[\begin{array}{lllll}0.50 & 0.35 & 0.10 & 0.05\end{array}\right]$ & 1.0678057 & 0.2690786 & 1.0992635 & 0.3303282 \\
\hline$P=\left[\begin{array}{lllll}0.50 & 0.30 & 0.15 & 0.05\end{array}\right]$ & 1.0928962 & 0.3186313 & 1.0949305 & 0.3224008 \\
\hline
\end{tabular}

Table 12. ARL for Known Proportions with $q=3$ and $n=300$.

\begin{tabular}{|c|c|c|c|c|}
\hline \multirow{3}{*}{ Baseline proportions } & \multicolumn{4}{|c|}{$n=300$} \\
\hline & \multicolumn{4}{|c|}{$q=4$} \\
\hline & $\mathrm{UCL}\left(Z_{i}^{2}\right)$ & $\operatorname{SDRL}\left(Z_{i}^{2}\right)$ & $\operatorname{UCL}\left(Y_{i}^{2}\right)$ & $\operatorname{SDRL}\left(Y_{i}^{2}\right)$ \\
\hline \multirow{3}{*}{$P=\left[\begin{array}{llll}0.7 & 0.2 & 0.1\end{array}\right]$} & 5.9914646 & 18.577242 & 12.064423 & \\
\hline & $\operatorname{ARL}\left(Z_{i}^{2}\right)$ & & $\operatorname{ARL}\left(Y_{i}^{2}\right)$ & \\
\hline & 19.083969 & & 19.96008 & \\
\hline Improvement & $\operatorname{ARL}\left(Z_{i}^{2}\right)$ & $\operatorname{SDRL}\left(Z_{i}^{2}\right)$ & $\operatorname{ARL}\left(Y_{i}^{2}\right)$ & $\operatorname{SDRL}\left(Y_{i}^{2}\right)$ \\
\hline$P=\left[\begin{array}{lll}0.75 & 0.20 & 0.05\end{array}\right]$ & 1.2189176 & 0.5165680 & 70.921986 & 70.420211 \\
\hline$P=\left[\begin{array}{lll}0.75 & 0.15 & 0.10\end{array}\right]$ & 2.0661157 & 1.4841558 & 2.0682523 & 1.4864102 \\
\hline$P=\left[\begin{array}{llll}0.76 & 0.20 & 0.04\end{array}\right]$ & 1.039177 & 0.2017717 & 74.074074 & 73.572375 \\
\hline$P=\left[\begin{array}{lll}0.78 & 0.16 & 0.06\end{array}\right]$ & 1.1944577 & 0.4819455 & 3.3557047 & 2.811592 \\
\hline$P=\left[\begin{array}{lll}0.80 & 0.10 & 0.10\end{array}\right]$ & 1.0049241 & 0.0703445 & 1.0042177 & 0.0650806 \\
\hline Deterioration & $\operatorname{ARL}\left(Z_{i}^{2}\right)$ & $\operatorname{SDRL}\left(Z_{i}^{2}\right)$ & $\operatorname{ARL}\left(Y_{i}^{2}\right)$ & $\operatorname{SDRL}\left(Y_{i}^{2}\right)$ \\
\hline$P=\left[\begin{array}{lll}0.68 & 0.20 & 0.12\end{array}\right]$ & 5.4112554 & 4.8857374 & 3.8774719 & 3.3402569 \\
\hline$P=\left[\begin{array}{lll}0.65 & 0.23 & 0.12\end{array}\right]$ & 2.463661 & 1.8989377 & 2.1710812 & 1.5945258 \\
\hline$P=\left[\begin{array}{llll}0.60 & 0.20 & 0.20\end{array}\right]$ & 1.002004 & 0.0448109 & 1.0006004 & 0.0245104 \\
\hline$P=\left[\begin{array}{llll}0.55 & 0.25 & 0.20\end{array}\right]$ & 1.0001 & 0.0100005 & 1 & 0 \\
\hline
\end{tabular}

Table 13. ARL for Known Proportions with $q=5$ and $n=100$.

\begin{tabular}{|c|c|c|c|c|}
\hline \multirow{2}{*}{ Baseline proportions } & \multicolumn{4}{|c|}{$n=100$} \\
\hline & \multicolumn{4}{|c|}{$q=5$} \\
\hline \multirow{4}{*}{$P=\left[\begin{array}{lllll}0.50 & 0.30 & 0.10 & 0.07 & 0.03\end{array}\right]$} & $\mathrm{UCL}\left(Z_{i}^{2}\right)$ & $\operatorname{SDRL}\left(z_{i}^{2}\right)$ & $\mathrm{UCL}\left(Y_{i}^{2}\right)$ & $\operatorname{SDRL}\left(Y_{i}^{2}\right)$ \\
\hline & 9.487729 & 19.062916 & 122.05381 & 19.453656 \\
\hline & $\operatorname{ARL}\left(z_{i}^{2}\right)$ & & $\operatorname{ARL}\left(Y_{i}^{2}\right)$ & \\
\hline & 19.569472 & & 19.96008 & \\
\hline Improvement & $\operatorname{ARL}\left(z_{i}^{2}\right)$ & $\operatorname{SDRL}\left(z_{i}^{2}\right)$ & $\operatorname{ARL}\left(Y_{i}^{2}\right)$ & $\operatorname{SDRL}\left(Y_{i}^{2}\right)$ \\
\hline$P=\left[\begin{array}{lllll}0.52 & 0.30 & 0.10 & 0.07 & 0.01\end{array}\right]$ & 16.528926 & 16.021126 & 99.009901 & 98.508632 \\
\hline
\end{tabular}


Table 13. Continued...

\begin{tabular}{ccccc}
\hline Baseline proportions & \multicolumn{4}{c}{$\mathbf{n = 1 0 0}$} \\
\cline { 2 - 5 } & & \multicolumn{4}{c}{$\mathbf{q}=\mathbf{5}$} \\
\hline $\mathrm{P}=\left[\begin{array}{lllll}0.55 & 0.30 & 0.10 & 0.02 & 0.03\end{array}\right]$ & 4.199916 & 3.6659758 & 26.525199 & 26.020396 \\
\hline $\mathrm{P}=\left[\begin{array}{lllll}0.55 & 0.30 & 0.05 & 0.07 & 0.03\end{array}\right]$ & 5.3763441 & 4.8506424 & 26.315789 & 25.810947 \\
\hline $\mathrm{P}=\left[\begin{array}{lllll}0.58 & 0.22 & 0.10 & 0.07 & 0.03\end{array}\right]$ & 3.9184953 & 3.3817318 & 4.3994721 & 3.8672836 \\
\hline $\mathrm{P}=\left[\begin{array}{lllll}0.60 & 0.27 & 0.09 & 0.03 & 0.01\end{array}\right]$ & 2.6226069 & 2.0628766 & 41.322314 & 40.819252 \\
\hline Deterioration & $\mathrm{ARL}\left(Z_{i}^{2}\right)$ & $\mathrm{SDRL}\left(Z_{i}^{2}\right)$ & $\mathrm{ARL}\left(Y_{i}^{2}\right)$ & $\mathrm{SDRL}\left(Y_{i}^{2}\right)$ \\
\hline $\mathrm{P}=\left[\begin{array}{lllll}0.48 & 0.30 & 0.10 & 0.07 & 0.05\end{array}\right]$ & 5.6338028 & 5.1093964 & 3.875969 & 3.3387373 \\
\hline $\mathrm{P}=\left[\begin{array}{lllll}0.43 & 0.30 & 0.17 & 0.07 & 0.03\end{array}\right]$ & 2.18436 & 1.6084367 & 4.2753313 & 3.7420751 \\
\hline $\mathrm{P}=\left[\begin{array}{lllll}0.43 & 0.37 & 0.10 & 0.07 & 0.03\end{array}\right]$ & 4.4802867 & 3.948757 & 4.456328 & 3.9246059 \\
\hline $\mathrm{P}=\left[\begin{array}{lllll}0.40 & 0.32 & 0.12 & 0.10 & 0.08\end{array}\right]$ & 1.7476407 & 3.948757 & 1.5807777 & 0.9581651 \\
\hline
\end{tabular}

Table 14. ARL for Known Proportions with $q=4$ and $n=100$.

\begin{tabular}{|c|c|c|c|c|}
\hline \multirow{2}{*}{ Baseline proportions } & \multicolumn{4}{|c|}{$n=100$} \\
\hline & & & $q=4$ & \\
\hline \multirow{4}{*}{$P=\left[\begin{array}{llll}0.60 & 0.25 & 0.10 & 0.05\end{array}\right]$} & $\mathrm{UCL}\left(Z_{i}^{2}\right)$ & $\operatorname{SDRL}\left(Z_{i}^{2}\right)$ & $\mathrm{UCL}\left(Y_{i}^{2}\right)$ & $\operatorname{SDRL}\left(Y_{i}^{2}\right)$ \\
\hline & 7.8147279 & 21.56926 & 32.038648 & 19.453656 \\
\hline & $\operatorname{ARL}\left(Z_{i}^{2}\right)$ & & $\operatorname{ARL}\left(Y_{i}^{2}\right)$ & \\
\hline & 22.075055 & & 19.96008 & \\
\hline Improvement & $\operatorname{ARL}\left(Z_{i}^{2}\right)$ & $\operatorname{SDRL}\left(z_{i}^{2}\right)$ & $\operatorname{ARL}\left(Y_{i}^{2}\right)$ & $\operatorname{SDRL}\left(Y_{i}^{2}\right)$ \\
\hline$P=\left[\begin{array}{llll}0.64 & 0.25 & 0.10 & 0.01\end{array}\right]$ & 6.0569352 & 5.5343951 & 151.51515 & 151.01432 \\
\hline$P=\left[\begin{array}{llll}0.65 & 0.25 & 0.05 & 0.05\end{array}\right]$ & 4.7641734 & 4.2347579 & 26.385224 & 25.88039 \\
\hline$P=\left[\begin{array}{llll}0.69 & 0.25 & 0.05 & 0.01\end{array}\right]$ & 1.699813 & 1.0906655 & 133.33333 & 132.83239 \\
\hline$P=\left[\begin{array}{llll}0.70 & 0.15 & 0.10 & 0.05\end{array}\right]$ & 1.9912386 & 1.4049173 & 1.9853087 & 1.3986214 \\
\hline$P=\left[\begin{array}{llll}0.75 & 0.15 & 0.05 & 0.05\end{array}\right]$ & 1.2674271 & 0.5821893 & 1.7979144 & 1.1977403 \\
\hline Deterioration & $\operatorname{ARL}\left(z_{i}^{2}\right)$ & $\operatorname{SDRL}\left(z_{i}^{2}\right)$ & $\operatorname{ARL}\left(Y_{i}^{2}\right)$ & $\operatorname{SDRL}\left(Y_{i}^{2}\right)$ \\
\hline$P=\left[\begin{array}{llll}0.55 & 0.25 & 0.10 & 0.10\end{array}\right]$ & 2.1181953 & 1.5390114 & 1.6594756 & 1.0461279 \\
\hline$P=\left[\begin{array}{llll}0.52 & 0.25 & 0.15 & 0.08\end{array}\right]$ & 1.9868865 & 1.4002969 & 1.9508389 & 1.3619594 \\
\hline$P=\left[\begin{array}{llll}0.50 & 0.35 & 0.10 & 0.05\end{array}\right]$ & 2.0395676 & 1.4561141 & 2.1168501 & 1.5375969 \\
\hline$P=\left[\begin{array}{llll}0.50 & 0.30 & 0.15 & 0.05\end{array}\right]$ & 2.1168501 & 1.5375969 & 2.093364 & 1.512881 \\
\hline
\end{tabular}

Table 15. ARL for Known Proportions with $q=3$ and $n=100$.

\begin{tabular}{|c|c|c|c|c|}
\hline \multirow{2}{*}{ Baseline proportions } & \multicolumn{4}{|c|}{$n=100$} \\
\hline & & & $q=3$ & \\
\hline \multirow{4}{*}{$P=\left[\begin{array}{lll}0.7 & 0.2 & 0.1\end{array}\right]$} & $\operatorname{UCL}\left(z_{i}^{2}\right)$ & $\operatorname{SDRL}\left(Z_{i}^{2}\right)$ & $\operatorname{UCL}\left(Y_{i}^{2}\right)$ & $\operatorname{SDRL}\left(Y_{i}^{2}\right)$ \\
\hline & 5.9914646 & 21.13911 & 11.79648 & 19.334806 \\
\hline & $\operatorname{ARL}\left(Z_{i}^{2}\right)$ & & $\operatorname{ARL}\left(Y_{i}^{2}\right)$ & \\
\hline & 21.645022 & & 19.84127 & \\
\hline Improvement & $\operatorname{ARL}\left(Z_{i}^{2}\right)$ & $\operatorname{SDRL}\left(Z_{i}^{2}\right)$ & $\operatorname{ARL}\left(Y_{i}^{2}\right)$ & $\operatorname{SDRL}\left(Y_{i}^{2}\right)$ \\
\hline$P=\left[\begin{array}{lll}0.75 & 0.20 & 0.05\end{array}\right]$ & 4.0866367 & 3.5516141 & 81.967213 & 81.465679 \\
\hline$P=\left[\begin{array}{lll}0.75 & 0.15 & 0.10\end{array}\right]$ & 6.0096154 & 5.4868809 & 6.4267352 & 5.9056067 \\
\hline$P=\left[\begin{array}{lll}0.76 & 0.20 & 0.04\end{array}\right]$ & 2.5826446 & 2.021734 & 75.757576 & 75.255915 \\
\hline$P=\left[\begin{array}{lll}0.78 & 0.16 & 0.06\end{array}\right]$ & 3.3590863 & 2.8150265 & 10.438413 & 9.9258276 \\
\hline$P=\left[\begin{array}{lll}0.80 & 0.10 & 0.10\end{array}\right]$ & 1.512173 & 0.8800535 & 1.5304561 & 0.9010215 \\
\hline Deterioration & $\operatorname{ARL}\left(z_{i}^{2}\right)$ & $\operatorname{SDRL}\left(z_{i}^{2}\right)$ & $\operatorname{ARL}\left(Y_{i}^{2}\right)$ & $\operatorname{SDRL}\left(Y_{i}^{2}\right)$ \\
\hline $\mathrm{P}=\left[\begin{array}{lll}0.68 & 0.20 & 0.12\end{array}\right]$ & 9.5785441 & 9.0647649 & 6.7204301 & 6.2003025 \\
\hline$P=\left[\begin{array}{lll}0.65 & 0.23 & 0.12\end{array}\right]$ & 5.7208238 & 5.1968261 & 4.4622936 & 3.9306196 \\
\hline $\mathrm{P}=\left[\begin{array}{llll}0.60 & 0.20 & 0.20\end{array}\right]$ & 1.2669454 & 0.5815542 & 1.1500863 & 0.4154662 \\
\hline$P=\left[\begin{array}{llll}0.55 & 0.25 & 0.20\end{array}\right]$ & 1.1082788 & 0.3464146 & 1.0625863 & 0.2578824 \\
\hline
\end{tabular}


The ARL and SDRL performance comparison for the case where $n=100,300,500$, 1000 and $q=3,4,5$ is shown in the previous tables. They reveal in case of process improvement, it would be better to use the WSCC. In fact, this chart has better performance compared to CSCC. Whereas, in the case of a process deterioration, the WSCC does not suggest better outcomes as to the CSCC.

Finally, The main strengths of the WSCC lies in:

1. In a case of quality deterioration, this chart allows a fast detection of an out-of-control situation;

2. On the contrary of Marccucci chart, an out-of-control situation is not quickly detected in the case of a quality improvement.

\section{Conclusion}

Processes with multiple categories can be modeled as multinomial processes. Marcucci (1985) proposed a method to monitor such processes. However, this method does not allow a differentiation between a process improvement or process deterioration, it indicates only if the process is out-of-control or not. Hence in this study we propose a Weighted sum of the chi-square control chart to monitor any multinomial processes. The basic concept of this chart is to enhance each category by weights.

The corresponding UCL is calculated using simulation. According to an ARL comparison, we succeed to demonstrate that the proposed method outperforms the Chisquare chart. In fact, the WSCC control chart does not only allow a faster detection of an out-of control situation in a case of quality deterioration but also outperforms the Marcucci method in the case of a quality improvement as it does not quickly detect an out-of control situation.

Future researches will focus on expanding the study on other approaches such as implementing a Weighted sum of the chi-square control chart with unknown proportions, i.e proportions are not specified and should be estimated. It is well known that when incontrol parameters are estimated, the performance of control charts differs from the known parameters case due to the variability of the estimators used during the Phase $\mathrm{I}$.

\section{References}

Duncan, A. J. (1950). A chi-square chart for controlling a set of percentages. Industrial Quality Control, 7, 11-15.

Duncan, A. J. (1974). Quality control and industrial statistics (4th ed.). Homewood, IL: Richard D. Irwin.

Feiveson, A. H., \& Delaney, F. C. (1968). A chi-square chart for controlling a set of percentages. industrial quality control (Vol. 38). Washington: National Aeronautics and Space Administration.

Kanagawa, A., Tamaki, F., \& Ohta, H. (1993). Control charts for process average and variability based on linguistic data. International Journal of Production Research, 31(4), 913-922. http://dx.doi.org/10.1080/00207549308956765.

Marcucci, M. (1985). Monitoring multinomial processes. Journal of Quality Technology, 17(2), 8691. http://dx.doi.org/10.1080/00224065.1985.11978941.

Nelson, L. S. (1987). A chi-square control chart for several proportions. Journal of Quality Technology, 19(4), 229-231. http://dx.doi.org/10.1080/00224065.1987.11979069. 
Raz, T., \& Wang, J. (1990). On the construction of control charts using linguistic variables. International Journal of Production Research, 28(3), 477-487.

http://dx.doi.org/10.1080/00207549008942731.

Shewhart, W. A. (1925). The application of statistics as an aid in maintaining quality of a manufactured product. Journal of the American Statistical Association, 20(152), 546-548. http://dx.doi.org/10.1080/01621459.1925.10502930.

Shewhart, W. A., \& Deming, W. E. (1939). Statistical method from the viewpoint of quality control. Washington: The Graduate School, The Department of Agriculture.

Steiner, S. H., Geyer, P. L., \& Wesolowsky, G. O. (1996). Shewhart control charts to detect mean and standard deviation shifts based on grouped data. Quality and Reliability Engineering International, 12(5), 345-353. http://dx.doi.org/10.1002/(SICI)10991638(199609)12:5<345::AID-QRE11>3.0.CO;2-M.

Taleb, H., Limam, M., \& Hirota, H. (2006). Multivariate fuzzy multinomial control charts. Quality Technology \& Quantitative Management, 3(4), 437-453. http://dx.doi.org/10.1080/16843703.2006.11673125.

Taleb, M., \& Limam, M. (2002). H.and Limam. On fuzzy and probabilistic control charts. International Journal of Production Research, 40(12), 2849-2863. http://dx.doi.org/10.1080/00207540210137602.

Topalidou, E., \& Psarakis', S. (2009). Review of multinomial and multi attribute quality control charts. Quality and Reliability Engineering International, 25(7), 773-804. http://dx.doi.org/10.1002/qre.999.

Tucker, G. R., Woodall, W. H., \& Tsui, K. L. (2002). control chart method for ordinal data. American Journal of Mathematical and Management Sciences, 22(1-2), 31-48. http://dx.doi.org/10.1080/01966324.2002.10737574.

Woodall, W. H. (1997). Control charts based on attribute data: bibliography and review. Journal of Quality Technology, 29(2), 172-183. http://dx.doi.org/10.1080/00224065.1997.11979748. 


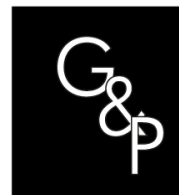

GESTÃO

PRODỰ̂̃O

ISSN 0104-530X (Print)

ISSN 1806-9649 (Online)

ERRATUM

\section{ERRATUM: Monitoring multinomial processes based on a weighted chi-square control chart}

Achouri Ali ${ }^{1}$ (D), Emira Khedhiri², Ramzi Talmoudi ${ }^{3} \mathbb{D}$, Hassen Taleb $^{1}$

${ }^{1}$ University of Carthage, ARBRE Laboratory, Tunis, Tunisia.

${ }^{2}$ University of Tunis, ARBRE Laboratory, Tunis, Tunisia.

${ }^{3}$ University of Carthage, ENVIE Laboratory LR18ES48, Nabeul, Tunisia.

Due to desktop publishing error the article "Monitoring multinomial processes based on a weighted chi-square control chart" (DOI https://doi.org/10.1590/1806-96492021v28e43), published in Gestão \& Produção, 28(3), e43, 2021, was published with an error.

On page 1, where the text reads:

ORIGINAL ARTICLE

It should read:

THEMATIC SECTION: STATISTICAL PROCESS MONITORING AND CONTROL The publisher apologizes for the errors. 